\title{
Localized Unresectable Adult Liver Carcinoma
}

National Cancer Institute

\section{Source}

National Cancer Institute. Localized Unresectable Adult Liver Carcinoma. NCI Thesaurus.

Code C7878.

A localized hepatocellular carcinoma or intrahepatic cholang iocarcinoma that occurs during adulthood and it is not amenable to surgical resection. 